\title{
A Review on Self-Healing Coatings Applied to Mg Alloys and Their Electrochemical Evaluation Techniques
}

\author{
Muhammad Junaid Anjum ${ }^{1}$, Jingmao Zhao ${ }^{1,2,{ }^{*}, \text { Hamid Ali }}{ }^{3}$, Mohammad Tabish ${ }^{1}$, Hassan Murtaza ${ }^{1}$, \\ Ghulam Yasin ${ }^{1}$, Muhammad Uzair Malik ${ }^{1}$, Waheed Qamar Khan ${ }^{4}$ \\ ${ }^{1}$ College of Materials Science and Engineering, Beijing University of Technology, Beijing, 100029, \\ PR China \\ ${ }^{2}$ Key Laboratory of Electrochemical Process and Technology for Materials, Beijing University of \\ Chemical Technology, Beijing 100029, China \\ ${ }^{3}$ Department of Mechanical Engineering, University of Engineering and Technology, Taxila, 47080, \\ Pakistan \\ ${ }^{4}$ Institute of Advanced Materials, Bahauddin Zakariya University, Multan 60800, Pakistan \\ *E-mail: jingmaozhao@126.com
}

doi: $10.20964 / 2020.04 .36$

Received: 10 September 2019 / Accepted: 5 February 2020 / Published: 10 March 2020

\begin{abstract}
Magnesium $(\mathrm{Mg}$ ) and its alloys are being used as substitutes for conventional structural materials due to their helpful characteristics, such as low density and exceptional mechanical properties. However, the electrochemical stability of $\mathrm{Mg}$ and its alloys inhibits their utilization in various applications. Therefore, the development of active self-healing coatings that can not only protect $\mathrm{Mg}$ alloys at the experimental scale but also be utilized at the commercial scale is imperative. The study of self-healing coatings for $\mathrm{Mg}$ alloys is increasing at an unexpected rate. However, the mechanisms of self-healing and their electrochemical evaluations for inorganic coatings are scarcely summarized for $\mathrm{Mg}$ alloys. In the present appraisal, a comprehensive overview is provided for both self-healing mechanisms and evaluation techniques that have been utilized for $\mathrm{Mg}$ alloys. Finally, a future perspective of self-healing coatings and evaluation techniques is provided that illuminates the lack of information that is available and confirms that a substantial amount of work is needed to fill those research area gaps for $\mathrm{Mg}$ alloys.
\end{abstract}

Keywords: Magnesium alloys, self-healing, evaluation techniques, coatings, electrochemistry

\section{FULL TEXT}

(C) 2020 The Authors. Published by ESG (www.electrochemsci.org). This article is an open access article distributed under the terms and conditions of the Creative Commons Attribution license (http://creativecommons.org/licenses/by/4.0/). 